\title{
Iracema e Farida: diálogos
}

\author{
Cristiane Barbosa Lira ${ }^{1}$
}

RESUMO: Este trabalho desenvolve, através da literatura comparada, um estudo das relações entre Terra sonâmbula (1992) de Mia Couto e Iracema (1865) de José de Alencar. Analisamos as personagens, Farida e Iracema. Embora inicialmente o que se apresente como comparativo seja a presença de duas mulheres, o que buscamos nos textos é como elas personificam a terra possuída pelo colonizador e como mulheres/terra estão marcadas pelo signo da presença do poder e da colonização.

ABSTRACT: This paper develops, through comparative literature, a study of the relationship between Terra Sonâmbula (1992) by Mia Couto and Iracema (1865)by José de Alencar. We analyze the female characters, Farida and Iracema. Although, initially what becomes more clear as a comparative point is the presence of two women, what we search for in these works is how the two characters personifies the land possessed by the colonizer, and as women/land marked them by the sign of the presence of the power and the colonization.

PALAVRAS-CHAVE: Terra Sonâmbula, Iracema, Mia Couto, José de Alencar, mulher, terra, poder.

KEYWORDS: Terra Sônambula, Iracema, Mia Couto, José de Alencar, woman, land, power.

O nosso trabalho desenvolve, dentro da esfera da literatura comparada, um estudo das relações entre Iracema ${ }^{2}$ (1865) de José de Alencar e Terra Sonâmbula ${ }^{3}$ (1992) de Mia Couto, na análise das ações de duas personagens dos livros mencionados. Em $I$, a personagem que dá nome ao romance, Iracema; em TS, Farida. Embora inicialmente o que se apresente como comparativo nessas obras, cronológica e esteticamente distintas, seja a presença de duas mulheres, o que

1 Doutoranda em Línguas Românicas com ênfase em literatura brasileira e hispanoamericana pela Universidade da Geórgia - Athens, Georgia, Estados Unidos. Defendeu recentemente a dissertação de mestrado entitulada, "Na prosa e na poesia: percursos do exílio em Ferreira Gullar”. Email: clira@uga.edu.

2 De agora em diante o livro será nomeado $I$.

${ }^{3}$ De agora em diante o livro será nomeado TS. 
buscaremos nos textos é como estas personificam a terra possuída pelo colonizador e como as mulheres e a terra têm sido marcadas pelo signo da presença do poder e da colonização.

Há entre as personagens de Iracema e Farida interações latentes que serão por nós pontuadas ao longo deste ensaio como alegoria $^{4}$ da presença e da ausência de diálogo, entendendo-se por este reciprocidade entre Brasil e Moçambique, nas obras em estudo. Iniciamos com a questão do anagrama presente no nome de Iracema, que já foi previamente apontada por Afrânio Peixoto em Noções de História da Literatura Brasileira, América, e o anagrama que existe no nome de Farida que é rifada. A palavra rifada foi por nós interpretada como um adjetivo que se espelha no substantivo rifa que significa, segundo o dicionário Celso Pedro Luft, "espécie de loteria, sorteio em que os prêmios são objetos e não dinheiro". Dessa maneira, Farida seria a alegoria da terra posta em sorteio entre os seus iguais e também os estrangeiros. Se em I, temos a presença do colonizador como força motriz para a morte da heroína e, em extensão lírica, da própria terra tomada pelos portugueses, haja vista que Martim diz "Venho das terras que teus irmãos já possuíram, e hoje têm os meus," (ALENCAR, 2000, p. 18) em TS, vemos a terra convulsionada pela guerra, destruída pelas mãos de seus próprios filhos. Assim, é possivel nos determos em Farida como símbolo da terra posta a prêmio, sendo disputada e mutilada enquanto Iracema simboliza a terra virgem recebendo o colonizador.

Partindo disso, chegamos também a outra leitura possivel ao nome Farida, haja vista que este se aproxima, sonoramente, da palavra ferida, apontando também as consequências da maculação do ventre da terra, esta é ferida e sonâmbula. Vê-se, portanto, através destes ferimentos, uma prerrogativa pós-moderna e especialmente diagnosticada na escrita de Couto, das constantes referências a, como definido por Maria Fonseca e Maria Cury em Mia Couto: espaços

\footnotetext{
${ }^{4}$ Uma vez que Farida e Iracema são personagens que aparecem em um contexto que não precisa ser somente lido como o apresentado. Antes, podem ser vistas como partes de um discurso no qual há "uma história que sugere outra" (MOISÉS, 2004, p.14).
} 
ficcionais, "espaços 'desmanchados', diluídos, fragmentados," (2008, p. 55) feridos, portanto.

Além da questão dos nomes que remete à condição fulcral de mulheres e alegoricamente símbolos da terra, ambas carregam em seu bojo a conotação de Eva. Em I, esta seduz o guerreiro branco. É interessante observarmos como Martim é completamente privado de qualquer culpa. Na história construída pela pena de Alencar, Martim é descrito como tendo muitos momentos de repressão aos próprios pensamentos, ao simples fato de desejar a virgem dos lábios de mel. Um dos momentos nos quais é possivel perceber a intenção narrativa de purificar a alma do guerreiro, apontando que ele era alvo de sentimentos que desconhecia e contra os quais sentia temor, é quando Martim diz, falando de si na terceira pessoa "o teu hóspede... não tem medo dos guerreiros de Irapuã; tem medo dos olhos da virgem de Tupã," (ALENCAR, p. 40) revelando, assim, que ela exerce algum poder sobre ele, neste caso, o de o seduzir. Lembrando, ainda, que ela guarda os segredos da jurema, logo, além da condição de fêmea, carrega também a conotação de feiticeira, atribuindo-se a ela outros dotes através desta condição. Como retomado por Silviano Santiago em "Alegoria e palavra em Iracema," ela representa o

caráter feminino que atrai pelas suas aparências o estrangeiro, e que até o enfeitiça através do licor da jurema, que... ministra a Martim para que ele, voltando à sua pátria pelo sonho, a despreze, distancie-se dos seus, e reclame Iracema no ato amoroso, cego, instintivo (1965, p. 63).

Logo, o enredo é construído de maneira a preservar os ideais morais do herói. Para isso apresenta, ainda, outros momentos em que ele se depara com crises de consciência. Um deles, por exemplo, é quando Martim "preme [Iracema] ao seio; e o lábio ávido busca o lábio que o espera, para celebrar nesse ádito d'alma, o himeneu do amor" (ALENCAR, p. 44) e, paralelamente a isso, ele ouve um gemido doloroso do Pajé e repele Iracema, "O cristão repeliu do seio a virgem indiana. Ele 
não deixará o rasto da desgraça na cabana hospedeira. Cerra os olhos para não ver; e enche sua alma com o nome e a veneração de seu Deus: - Cristo!... Cristo!..."(ALENCAR, p. 44). Iracema, assim, é totalmente responsabilizada, através da tessitura narrativa, pelos atos que levam à entrega, haja vista que esta droga Martim e quando ele está sob o efeito do licor da jurema, Iracema - praticamente - valendo-nos de um termo popular - aproveita-se do guerreiro - para assim saciar o desejo que também the consome. Ele, por sua vez, quando acorda e vê a índia "unida ao seu coração, cuidou que o sonho continuava; cerrou os olhos para torná-los a abrir" (ALENCAR, p. 45) exumando-se, assim, de toda e qualquer culpa e elevando Iracema, como proposto por Eduardo Duarte em "Iracema: a expansão portuguesa sob o signo de Eva," à condição de Eva, denotando sobre ele todo

o maniqueísmo do discurso falocêntrico [que] debita à mulher e à sua magia telúrica todo o poder de sedução, fazendo do homem uma vítima. Sob o efeito do licor, pode Martim transgredir o código moral da narrativa sem que nenhum pecado the pese na consciência. Iracema, ao contrário, mais que nunca cumpre o papel de Eva, já que, deliberadamente, incita e fornece os meios para que se consuma a violação (1999, p. 199).

Desfloramente este, aliás, que não pode ser considerado, exatamente, uma violação, haja vista que Iracema se entrega àquele que ela deseja ou, valendo-nos das observações de Silviano Santiago, "a violência não fora cometida, pelo menos lucidamente, mas a união se realizou" (1965, p. 65).

Em via semelhante e ao mesmo tempo de distanciamento, temos a presença de Farida em TS. Neste, vemos duas esferas relacionadas à personagem. A primeira é aquela designada por sua condição em relação ao português Romão Pinto. Farida é uma jovem proscrita devido às condições de seu nascimento - lembremos de que ela tinha uma irmã gêmea e, segundo a tradição, as crianças deveriam ser sacrificadas, - em decorrência deste destino, torna-se errante, 
Já tinha tomado a decisão de partir. Aquele lugar já estava cansado dela. Se lançou na estrada, sem nada senão roupas. Andou, andou, andou. Passou-se uma noite, uma manhã. O sol perpendiculava-se quando the veio uma tontura e abandonou todos os sentidos. Desmaiou (COUTO, 1992, p. 81).

É a partir daí que Farida é levada à casa da portuguesa Virgínia, que há de criá-la como se fosse uma filha. Neste lar, Farida, quando conta a sua história a Kindzu, comenta que ela

cresceu, [e] ali lhe despontaram os seios, ali se tornou mulher. Foi nesta casa que, pela primeira vez, sentiu os olhos de um homem salivando. Romão Pinto lhe perseguia, suas mãos não paravam de lhe procurar. Às vezes, de noite, espreitava pela janela enquanto ela tomava banho. Farida estava cercada, indefesa (COUTO, p. 81).

Vemos que a narrativa usa meios peculiares de descrever, mesmo que pela voz de Farida, a construção do desejo de Romão Pinto por ela. Inicialmente, ele é o sujeito da ação, afinal, ele a perseguia, na sequência, quem assume a ação, por viés metonímico, são as mãos dele, como se estas tivessem vontade própria e agissem contra os desejos daquele que as possui, Romão Pinto. Além disso, ainda que seja comum na língua portuguesa a adoção do sujeito oculto, facilmente reconhecido pela terminação verbal, é interessante como a próxima sentença é construída, haja vista que a anterior possui o sujeito simples as mãos, sem sujeito explícito, carregando o discurso de uma ausência de agentes, "espreitava pela janela enquanto ela tomava banho". Demonstrando, assim, através destas lacunas, o que mais tarde Farida revelará amplamente: o discurso da dominação sem agentes, sem culpados.

O romance se desenvolve e temos conhecimento dos movimentos de Virgínia para tirar Farida daquele lugar, pois ali ela não estaria segura. Farida é assim levada para uma missão. Ela fica por lá durante algum tempo, até que decide que deve voltar à sua aldeia, que aquele 
espaço transitório já não é o bastante para ela. Nesse retorno, passa pela casa de Romão Pinto e decide ir até lá para se despedir de Virgínia. Notamos aqui, portanto, que Farida é quem toma a iniciativa de voltar ao lugar que era sintoma de perigo para ela. Romão Pinto não vai procurá-la, ela vai até ele. Já estando em sua casa, Farida toma conhecimento da ausência de Virginia e embora tenha a oportunidade de ir embora, ela lá se hospeda pela noite à espera. Virginia, porém, nunca chega. O que se aproxima somente é Romão que já não age de maneira indireta, ronda o leito de Farida e ela não reage à sua presença, somente reza e questiona-se em silêncio do porquê de Deus demorar tanto. Nesse trecho, novamente, a ação é descrita em aspectos metonímicos: "seus braços procuraram no escuro"; "Quando seus dedos roçaram o rosto da menina," (COUTO, p. 85) denotando certo deslizamento do agente da ação. Finalmente, depois das investidas, temos acesso às ações de Farida que já estava cansada de esperar pela providência divina,

Desistiu de esperar e se ergueu de um salto, escapulada, tirando o corpo do alcance das babas do Romão. Surpreso, o português trancou a voz nos dentes, soprando ameaças. Memórias antigas da raça lhe avisaram: melhor seria ela se deixar, sem menção nem intenção. O português se homenzarrou, abusando dela toda inteira (COUTO, p. 85-6).

Nota-se que embora Farida tivesse a oportunidade de fazer algo para fugir àquela situação, imperaram nela as noções comentadas por Reich, conforme apresentado por Guido Mantega em "Sexo e poder nas sociedades autoritárias: a face erótica da dominação," de que "a sociedade autoritária cria indivíduos submissos, com forte ânsia de dominação, sempre almejando controlar os mais fracos para enganar sua sensação de impotência" (1979, p. 20). Farida, em sua condição de menina-mulher e com as tais memórias da raça não luta contra a violação, antes a aceita como um fato que já vem sendo feito e desfeito ao longo dos anos. 
Vê-se, assim, como apresentado por Cury e Fonseca, que "a violência de Romão contra Farida pode ser entendida como metonímia de outras apropriações: da terra e do corpo dos africanos" (2008, p. 50). Logo, tanto Iracema quanto Farida são possuídas, uma pelo viés de seu próprio desejo espelhado no desejo do outro e a segunda sem qualquer reciprocidade, somente a repulsa e a resignação. Entretanto, em ambos os romances fica claro, através da construção de uma narrativa centrada no benefício masculino, de que eles não são agentes de suas ações. O próprio Romão, por exemplo, só tomou posse do corpo inocente de Farida, pois ela, nas circunstâncias do texto, foi até ele, quase como entrega, ou como o fruto proibido a tentar-lhe.

A segunda esfera que também relacionamos à Farida está ligada ao fato desta ser a responsável pela atração de Kindzu até o navio no qual ela está. Se considerarmos os apontamentos de Robert Moser em seu ensaio “Terra Sonâmbula: manifestações de uma 'Odisséia' africana no Moçambique pós-independência," a respeito de como é possível verificarmos os paralelos épicos dentro do romance TS, vemos em Kindzu os aspectos do herói, tal como Ulisses, que está em trânsito na incessável busca por Ítaca. Nesse percurso, Kindzu é surpreendido por aspectos fantásticos por ordem do destino e de entidades externas ao real, além da própria bebedeira, "bebi, porém, bastante de mais. Pois, pela madrugada, já não me tinha no corpo" (COUTO, p. 63). Logo, quando se surpreende já em águas perdidas, percebe que "qualquer coisa [lhe] chamava nem [ele] sabia se dentro ou se fora [dele]" (COUTO, p. 63). Observa-se que ele sai do campo de tomada de decisões e já começa a atribuir seus movimentos a alguma força superior que o puxava.

Além disso, na sequência, ocorre uma intempérie meteorológica. Segundo Kindzu, "[o]s céus se arrebentaram e as nuvens, sem amparo, tombaram sobre a terra. Sobre a minha canoa se acenderam relâmpagos, vieram as chuvas, diluviando toda a paisagem" (COUTO, p. 63). Partindo da narrativa, vê-se a recorrência da "tópica do mau tempo." Como apresenta Bellei, valendo-se da leitura de Phillip Young e 
Peter Hulme, em "A virgem dos lábios sem mel," a "tópica do mau tempo' tende a ocorrer quando o aventureiro em terra estranha explica ao nativo que ali aportou por acaso, ao se separar de seus companheiros e se perder" (1999, p. 70). No caso de Kindzu, estritamente, ele não se perdeu de ninguém, mas foi providencialmente encaminhado ao lugar onde está Farida e, com isto, sua verdade inicial - tornar-se um naparama ${ }^{5}$ - tomará uma nova dimensão a partir dos acontecimentos que irão se desenvolver após este encontro, afinal Farida dará um outro rumo à sua busca: encontrar o filho dela, Gaspar.

Kindzu, também, envolve-se com Farida de tal maneira que se sente engendrado por ela como se a cada história que ela contasse, ele fosse sendo costurado, tecido a ela em um ritual infindo. Aliás, Farida revela a ele, comparando-se, em uma atmosfera análoga, às sereias, que "escuta, Kindzu: sabes quem te guiou até aqui? Não acreditas nos xipocos? Pois eu sou da família dos xipocos,”(COUTO, p. 91) evidenciando, também, a sua proximidade com nuances fantásticas e de feitiço, arrematando "eu já tinha te visto desse outro lado, mas as tuas linhas eram de água, teu rosto era cacimbo. Fui eu que te trouxe, fui eu que te chamei" (COUTO, p. 91). Logo, tanto quanto em Iracema, Farida se vale de determinados artefatos mágicos para a atração do herói.

Além disso, embora a cena do encontro de ambos não seja exatamente a mesma que inicia o encontro entre Martim e Iracema, vemos determinada ressonância entre estas quando nos detemos na observação da cena que antecede o ato sexual entre Kindzu e Farida, pois "por entre as cortinas vi o corpo de Farida, Ela se banhava" (COUTO, p. 106) e "Iracema saiu do banho... Rumor suspeito quebra a doce harmonia da sesta. Ergue a virgem os olhos, que o sol não deslumbra; sua vista perturba-se. Diante dela e todo a contemplá-la, está um guerreiro estranho" (ALENCAR, p. 17). Assim, em nossa leitura, ambas narrativas constroem-se em um viés patriarcal, apontando a

5 Que suscita a ideia de herói. Aquele que luta pela justiça, evitando, sobretudo, a destruição das guerras e dos desentendimentos. 
mulher que convida o homem, que o seduz, colocando-o em uma esfera de total passividade, à mercê dos encantos da fêmea, sem qualquer domínio dos próprios sentidos ou mutilado, como ocorre em maior frequência em TS, em fragmentos metonímicos, "um dedo foi entrando no canto da sua boca... Outro dedo caminhou nos interiores dela, nervoso de contente" (COUTO, p. 106). Finalmente, fixam-se os apontamentos de Moser, "a relação de Kindzu com Farida, a gêmea fragmentada e sonhadora, assume as dimensões de uma prova à tentação" (2003, p. 143) e Kindzu se firma, ao lado de Martim, como um herói estrangeiro mesmo sendo da mesma terra. Aliás, é interessante destacar isso, uma vez que a terra sonâmbula é aquela que convulsiona por conta das guerras, onde o povo não tem identificação com o mesmo povo dentro da mesma terra, mesmo Kindzu sendo moçambicano, ele é chamado de estrangeiro em boa parte de seu percurso. Veja-se um exemplo quando ele está em um bar em Matimati e um homem chega dizendo "[v]ocê estrangeiro, escuta. Nesta terra se passam muitas merdas, todos tem medo de falar" (COUTO, p. 140) ou quando ele estabelece contato com Quintino que diz, "vou lhe contar a minha estória, estrangeiro" (COUTO, p. 154) ao que Kindzu o corrige emendando, "Kindzu," reinventando uma condição de exilio ${ }^{6}$ e estranhamento dentro do próprio país, somente propício, pois "em Terra Sonâmbula, a terra é apreendida na Guerra, na destruição que a devasta. Percebida na sua errância sonâmbula, escapa à fixidez expressiva" (CURY e FONSECA, p. 127).

Ainda sobre as relações entre $I$ e TS, julgamos importante ressaltar, após o itinerário por nós percorrido, a questão temporal do romance como reflexo do seu tempo. Em $I$, vemos as vigorações do Romantismo e este em muito se liga, no Brasil, a recente independência do país. Com esta, segundo os apontamentos de Santiago, ao invés de uma abertura em todos os âmbitos, como ocorrera com os portos, houve, na verdade, um encasulamento político e literário. De acordo

${ }^{6}$ Fazemos uma análise breve do exílio na obra Terra sonâmbula no capítulo da nossa dissertação de mestrado entitulada "Na prosa e na poesia: percursos do exílio em Ferreira Gullar". 
com o crítico, não é admirável, "pois, que a literatura passe a ser, mais do que antes, forma e expressão do nacionalismo nascente, e que dois dos principais temas do Romantismo europeu aqui aportem e recebam as cores verde-amarela: a descrição da natureza e o indianismo" (p. 56). É com esta roupagem que temos a criação da virgem com os cabelos mais negros que a asa da graúna. I trará em seu escopo aquilo que Haroldo de Campos, citado por Bellei, aponta como a grande arte de Alencar, haja vista que o romance traz marcada em si a "invenção de uma linguagem poética original produzida pela hibridização do português e do tupi. Essencialmente, [Alencar se torna] um criador de linguagem original" (p. 65). Observa-se, em estágio paralelo, embora em outro período histórico, a mesma construção na tessitura narrativa de Mia Couto. Ele mescla em sua escrita termos típicos das línguas nativas de Moçambique além de se valer de neologismos para que a linguagem se reinvente em uma eterna tentativa pela busca de termos capazes de expressar os sentimentos que a pós-modernidade exige.

Daí colocar em comparação o fato de que também TS é publicado poucos anos depois da independência de Moçambique, sendo que este ainda estava sofrendo as consequências da guerra civil. Logo, notamos, tal qual reflexo distorcido, as palavras do crítico Carlos Faraco em seu ensaio, que toma de empréstimo como título os primeiros versos do poema "Minha Terra" de Casimiro de Abreu - "Todos cantam sua terra/também vou cantar a minha-," de que

o brasileiro [e também o moçambicano] buscava[m] ansiosamente uma resposta à pergunta: 'Afinal, quem somos nós?' Coisa muito natural numa sociedade desestruturada, que tinha conquistado sua independência política mas sentia-se carente de heróis, [caso do Brasil], e de uma identidade própria, [no caso de ambos os países] (2000, p. 14).

Dessa maneira, as duas obras buscam uma forma de dar a luz à nova nação concebendo heroínas que geram filhos. Em uma, reflexo de seu tempo, temos a visão romântica e idealizada, a virgem que se 
entrega em sacrificio. Na outra, reflexo também de seu tempo, já não existe sacrifício, tudo é fragmentado, despedaçado, em um mundo que não faz qualquer sentido, permeado de estradas mortas por onde pessoas passam sem consciência do solo que pisam ou do que são de fato, se seres humanos se somente bichos, como exemplifica o processo de animalização de Junhito em TS.

Retomando a ideia de concepção e as relações latentes entre Iracema e Farida, vemos que é a partir do relacionamento delas com os colonizadores - ou o homem branco - que são gerados filhos e estes são símbolos da mistura entre o velho e o novo, o branco e o negro, o índio e o branco, o interno e o externo, pensando em $I$; ou a total quebra de fronteiras entre o nativo e o estrangeiro, se pensarmos em TS. Através dessas relações é que ambas, Iracema e Farida, podem ser compreendidas como as mães que darão à terra as novas gerações e estas são marcadas pelo misto.

Em I, Moacir, o filho da dor, é aquele que é chamado de "o primeiro cearense," (ALENCAR, p. 137) reiterando as noções pelas quais o livro é apresentado, Lenda do Ceará, "[t]ratando-se, pois, como retomado por Regina Zilberman em 'Natureza e mulher: uma visão do Brasil no romance romântico,' de um mito de origem, que vai relatar a fundação da sociedade brasileira" (1989, p. 54). Além disso, o próprio romance dá rumos a Moacir quando aponta que este "emigrava da terra da pátria. Havia aí a predestinação de uma raça?” (ALENCAR, p. 137) deixando na dúvida as certezas que o tempo histórico já era possível de responder por si só.

Na mesma linha, em TS, temos Gaspar que é uma criança no cenário que se coloca com o pós-independência: ele não sabe quem ele é, não lembra dos seus pais, do seu passado e tem toda a sua infância destruída em pedaços. Quando a narrativa tenta demonstrar as reconstruções, vê-se que neste cenário não há espaço para ser criança, "quando iniciaram a viagem já ele se acostumava de cantar, dando vaga a distraídas brincriações. No convívio com a solidão, porém, o canto acabou por migrar de si. Os dois caminheiros condiziam com a estrada, 
murchos e desesperançados" (COUTO, p. 10). Logo, já não existe em uma terra sonâmbula, a possilibilidade romântica de idealização. Há somente o real permeado de fantasias e o som de "tiros suc[essivos], gritos, nuvens, a gente catando os capins para descobrir um urgente esconderijo" (COUTO, p. 130). Entretanto, mesmo em uma terra como esta, vê-se a possibilidade dos interstícios entre uma bala e outra, estabelecida na capacidade humana passada através das gerações da preservação e continuação da história através do exercício do sonho e reinvenção das histórias dentro da história, construindo e reconstruindo, despertando e adormecendo o povo que sofre.

Através da análise que nós nos propusemos a desenvolver, conseguimos observar os trânsitos da escrita alencariana e a maneira como se valeu de uma prosa poética muito confiante, trazendo ao escopo do romance uma escrita de elevado nível estético, não só na tentativa de contar a história, mas, dando a esta uma melodia talvez recuperada do desejo de preservar algo mais primitivo como, por exemplo, a fala indígena. Do mesmo modo, em Terra sonâmbula, Mia Couto, através da tessitura narrativa entre duas temporalidades - a história narrada e a história lida - trança os destinos, fazendo com que exista um diálogo constante entre a oralidade e a escrita, recuperando, em algum nível, o ideal já anteriormente proposto por Alencar. Finalmente, da aproximação dessas duas obras que antes pareciam tão distantes no tempo e no espaço, vemos que a figura feminina, aqui representada por Iracema e Farida, tem sido utilizada de maneira alegórica. Isto ocorre na tentativa de apresentar processos relacionados a questões de poder e dominação, através, também, da utilização do termo "terra" como sendo o elemento que precisa ser subjugado. Revelase, com isso, que mesmo com a passagem do tempo e o deslocamento espacial, algumas imagens e condições parecem estar sempre retornando, despertando do passado e chegando ao presente, tais e quais os movimentos de uma terra sonâmbula. 


\section{Referências bibliográficas}

ALENCAR, José de. Iracema. São Paulo: Ática, 2000.

BELLEI, Sérgio. “A virgem dos lábios sem mel." Luso-Brazilian Review. Vol.36, No.2 (Winter, 1999). p. 63-80.

COUTO, Mia. Terra sonâmbula. Lisboa: Editorial Caminho, 1992.

CURY, Maria \& FONSECA, Maria. Mia Couto: espaços ficcionais. Belo Horizonte: Autêntica editora, 2008.

DUARTE, Eduardo. "Iracema: a expansão portuguesa sob o signo de Eva." Literatura e feminismo: propostas teóricas e reflexões criticas. Rio de Janeiro: Elo editora, 1999.

FARACO, Carlos. "Todos cantam sua terra/também vou cantar a minha.” Iracema. São Paulo: Ática, 2000.

LIRA, Cristiane B. "Na prosa e na poesia: percursos do exílio em Ferreira Gullar", 2011. 175f. Dissertação (Mestrado em Línguas Românicas: Literatura brasileira) - Departamento de Linguas Românicas, Universidade da Geórgia, Geórgia, Estados Unidos, 2011.

LUFT, Celso Pedro. Minidicionário Luft. Ática: São Paulo, 1999.

MANTEGA, Guido. "Sexo e poder nas sociedades autoritárias: a face erótica da dominação." Sexo \& Poder. São Paulo: Editora brasiliense, 1979 . 
MOISÉS, Massaud. Dicionário de termos literários. São Paulo, Cultrix, 2004.

MOSER, Robert H. “Terra sonâmbula: Manifestações de uma 'Odisséia' africana no Moçambique pós-independência.” Reevaluating Mozambique. 2003.

SANTIAGO, Silviano. "Alegoria e palavra em Iracema." Luso-Brazilian Review. Vol.2, No.2 (Winter, 1965). p. 55-68.

ZILBERMAN, Regina. "Natureza e mulher: uma visão do Brasil no romance romântico." Modern Language Studies. Vol.19, No.2 (Spring, 1989). p. 50-64. 